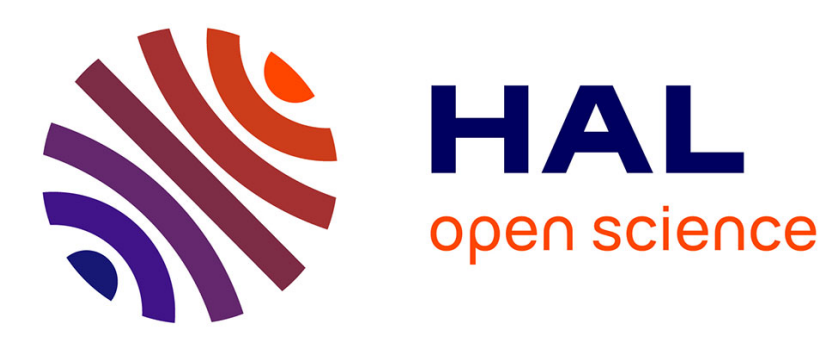

\title{
A mixed seismic-aseismic stress release episode in the Andean subduction zone
}

Juan carlos Villegas-Lanza, J.-M. Nocquet, Frédérique Rolandone, M. Vallée, H. Tavera, F. Bondoux, T. Tran, X. Martin, M. Chlieh

\section{- To cite this version:}

Juan carlos Villegas-Lanza, J.-M. Nocquet, Frédérique Rolandone, M. Vallée, H. Tavera, et al.. A mixed seismic-aseismic stress release episode in the Andean subduction zone. Nature Geoscience, 2016, 9 (2), pp.150-154 10.1038/ngeo2620 . hal-01285529

\section{HAL Id: hal-01285529 \\ https://hal.sorbonne-universite.fr/hal-01285529}

Submitted on 9 Mar 2016

HAL is a multi-disciplinary open access archive for the deposit and dissemination of scientific research documents, whether they are published or not. The documents may come from teaching and research institutions in France or abroad, or from public or private research centers.
L'archive ouverte pluridisciplinaire HAL, est destinée au dépôt et à la diffusion de documents scientifiques de niveau recherche, publiés ou non, émanant des établissements d'enseignement et de recherche français ou étrangers, des laboratoires publics ou privés. 


\section{A mixed seismic/aseismic stress release sequence at the northern Peru}

\section{subduction zone}

J.C. Villegas-Lanza ${ }^{1,2}$, J.-M. Nocquet ${ }^{2}$, F. Rolandone ${ }^{3}$, M. Vallée ${ }^{4}$, H. Tavera ${ }^{1}$, F. Bondoux ${ }^{5}$, T. Tran ${ }^{2, *}$, X. Martin ${ }^{2}$, M. Chlieh ${ }^{2}$.

${ }^{1}$ Instituto Geofísico del Perú, Calle Badajoz 169, Urbanización Mayorazgo IV Etapa, Ate, Lima, Perú.

${ }^{2}$ Geoazur, IRD, Université de Nice Sophia-Antipolis, Observatoire de la Côte d'Azur, CNRS, 250, rue A. Einstein, Valbonne, France.

${ }^{3}$ Sorbonne Universités, UPMC Univ Paris 06, CNRS UMR7193, ISTeP, F-75005, Paris, France.

${ }^{4}$ Institut de Physique du globe de Paris, Sorbonne Paris Cité, Université Paris Diderot, UMR 7154 CNRS, Paris, France.

${ }^{5}$ Géosciences Environnement Toulouse, Université Paul Sabatier, IRD, CNRS, Observatoire Midi-Pyrénées, Toulouse, France.

* (now at) National University of Civil Engineering, 55, Giai Phong road, Hai Ba Trung district, Hanoi Vietnam.

Subduction megathrusts release stress through earthquakes and transient aseismic slip that falls into two categories. Slow slip events emerge spontaneously during the interseismic phase ${ }^{1,2}$ and are often accompanied by tremors ${ }^{3,4}$ or synchronous microseismicity ${ }^{5-7}$. Afterslip occurs after large and moderate earthquakes, decelerates through time and releases $20-400 \%$ of the triggering earthquake moment ${ }^{2,8,9}$. Here, we document a seismic/aseismic stress release sequence that departs from previously observed transient slip. The sequence took place at shallow depth $(<25 \mathrm{~km})$ along the weakly coupled northern Peru subduction zone ${ }^{10}$ and lasted 7 months. The synchronous seismicity involving $M_{w}$ 5.8-6.0 events accounts for $\sim 25 \%$ of the total moment release, 
equivalent to $M_{\mathrm{w}}$ 6.7. Unlike slow slip events which show a progressive acceleration of slip $^{1-5,7,11-13}$, the transient slip started immediately after two earthquakes, before slowing down at logarithmic decay. The Mw 5.8 earthquake which was followed by the largest acceleration and slip amount shares most characteristics of tsunami earthquakes. Considered separately, the moment released following this latter earthquake is $>1000 \%$ of the co-seismic moment and the observed transient slip cannot be explained by classical models of afterslip. Synchronous Slow Slip and Seismic Swarm therefore define a stress release process distinct from slow slip events and afterslip.

Transient aseismic slip geodetically documented in subduction zones show a great diversity of size, duration, temporal evolution of slip and seismic signature. Slow Slip Events (SSE) lasting from weeks to months occur at depth of $\sim 40 \mathrm{~km}$, down-dip of the highly coupled portion of the subduction interface ${ }^{1-3}$. They often correlate with episodes of nonvolcanic tremors $(\mathrm{NVT})^{2-4}$, contributing at most to $0.1 \%$ of the total moment released during the $\mathrm{SSE}^{14}$. SSE detected in shallowly $(<20 \mathrm{~km})$ coupled subduction zones show duration of days to weeks ${ }^{5-7,12-13}$. They usually are associated with intense microseismicity bursts taking place inside or close to the slip area ${ }^{5-7}$, although non-volcanic tremors may also coexist ${ }^{15}$. In all cases of SSE documented so far, tremors and regular seismicity accounts for at most a few percent $(1-3 \%)$ of the total moment released ${ }^{5-7}$. Slow transient slip during days to months following moderate to large earthquakes, referred as afterslip, has been extensively documented $^{2,8}$. This process occurs in areas adjacent to the seismically ruptured zone (e.g. ref. $^{16}$ ) and its cumulative moment is usually 20 to $100 \%$ of the moment released by the earthquake $e^{2,8}$. Some cases of unusually large afterslip (100-400\% of the co-seismic moment) have also been reported following moderate to large earthquakes in the Japan ${ }^{9,17-18}$ and Kamtchaka $^{19}$ subduction zones. Thus, the aseismic/seismic moment ratio of processes releasing stress at subduction megathrust varies by 4 orders of magnitude, from $10^{-1}$ to $10^{0}$ for 
earthquakes-afterslip sequences to $10^{2}-10^{3}$ for SSE, with a gap of processes with aseismic/seismic moment ratio of $10^{1}$.

Here, we use geodetic and seismological observations (Figs. 1 and 2) to document a sequence mixing aseismic and seismic slip, both contributing significantly to the total moment release. The sequence took place in northern Peru where the oceanic Nazca plate subducts predominantly aseismically beneath the Inca continental sliver at $59 \mathrm{~mm} / \mathrm{yr}^{10}$. Northern Peru never experienced any great earthquake during the past five centuries, but hosted two significant earthquakes in $1960\left(M_{\mathrm{w}} 7.6\right)^{20}$ and $1996\left(M_{\mathrm{w}} 7.5\right)^{21}$. Both events were categorized as tsunami earthquakes because of their abnormally long source duration, enhanced long-period source spectrum, and the relatively large induced tsunami, with run-up height exceeding $5 \mathrm{~m}$ for the $1996^{21}$ and $9 \mathrm{~m}$ for the 1960 event $^{20}$.

The 2009 sequence studied here occurred north of the rupture of the 1960 tsunami earthquake, possibly overlapping with it. A transient trenchward displacement is seen at the continuous GPS site BAYO, lasting 7 months from February to September 2009 with a cumulative westward displacement of $14 \mathrm{~mm}$ (Fig. 1). Inversion of the slip distribution using geodetic displacements at 11 sites indicates that the main area of slip took place at shallow depth $(<25 \mathrm{~km})$ along the subduction interface, involving a patch of $90 \mathrm{~km}$ of diameter (Fig. 2f). The maximum slip reaches $45-50 \mathrm{~mm}$ and the equivalent moment release is $M_{\mathrm{w}} 6.7-6.8$. Between February and September 2009, the seismicity recorded by both the National Seismic Network of Peru and a temporary broadband seismometers network shows a sharp increase with more than one hundred events with magnitude ranging from 2.9 to 6.0 , all located inside or close to the slip area. The moment released through earthquakes is equivalent to $M_{\mathrm{w}} 6.3$, indicating that the process was $\sim 70-85 \%$ aseismic. 
The GPS time series at BAYO (Fig. 1) further shows that the slip evolved through time with phases of acceleration, which correlate with the occurrence of the major earthquakes, before a final phase of deceleration that lasted five months (Fig. 1). The recorded seismicity also shows a spatial and temporal organization related to the occurrence of the major events, followed by a five months period of relative quiescence (Fig. 2). In the following, we describe the different phases of the sequence and discuss their implications on the triggering process and on the frictional anatomy of the plate interface. Our interpretation is illustrated in figure 4.

Prior to the sequence, interseismic GPS velocities indicate that the plate interface is predominantly creeping ${ }^{10}$, therefore implying a dominant velocity-strengthening friction regime. The Bayovar area shows regular moderate seismicity, with $\sim 20$ interface events in the magnitude range of $M_{\mathrm{w}}$ 5.1-6.0 recorded since $1976^{22}$. The occurrence of moderate interface earthquakes indicates the existence of locked velocity-weakening patches with typical size of 0.1 to $10 \mathrm{~km}$, but still too small and too sparse to induce significant strain rate detectable by GPS during the interseismic period (Fig. 4ab).

The sequence studied here started at a depth of $\sim 12 \mathrm{~km}, \sim 30 \mathrm{~km}$ East from the trench. On February 82009 , a series of four foreshocks $\left(M_{\mathrm{w}} 3.9\right.$ to 4.9$)$ preceded by 20 hours to 30 min, a $M_{\mathrm{w}} 5.9$ thrust interface earthquake that occurred on February 9.8 aftershocks $\left(M_{\mathrm{w}} 3.1\right.$ to 4.2) were detected in the two days following the main shock (Fig. 2a \& 4c). Because the seismic sub-sequence took place about $\sim 100 \mathrm{~km}$ from the Peruvian coast, we could not observe whether it was associated with some aseismic slip or not.

The second sub-sequence started 3 days later, at $\sim 20-25 \mathrm{~km}$ depth, $\sim 100 \mathrm{~km}$ northeast from the first sub-sequence (Fig. $2 \mathrm{~b} \& 4 \mathrm{~d})$ with 8 foreshocks $\left(M_{\mathrm{w}} 3.2\right.$ to 4.6$)$ preceding by 30 hours to $10 \mathrm{~min}$ an interplate earthquake $\left(M_{\mathrm{w}} 6.0\right)$ on February 15.38 aftershocks with $M_{\mathrm{w}}$ 
2.9-4.2 occurred during the following five weeks. For both February events, the aftershocks are spatially clustered close to the epicenter, and occurred within a few days following the main shock as commonly observed for $M_{\mathrm{w}} \sim 5.9-6.0$ earthquakes. Also, for both events, no clear transient signal is seen in the GPS time series prior to the main shock, indicating that if transient aseismic slip existed, it was small. By contrast, a transient slip is evidenced by the GPS time series at BAYO after the February 15 earthquake with a trenchward displacement of $\sim 4 \mathrm{~mm}$ during the next 39 days (Fig. 1). Because, transient slip for this period is not detected at the other CGPS site PIU0 (Extended Data Figure 2), the transient signal seen at BAYO probably reflects some afterslip occurring in the immediate vicinity of the February 15 earthquake (Fig. 4d).

The next event (March 26, $\left.M_{\mathrm{w}} 5.8\right)$ occurred at very shallow ( 8 $\left.\mathrm{km}\right)$ depth, close to the trench. Its characteristics depart from the two previous events, with neither foreshocks nor clear sequence of spatially and timely clustered aftershocks (Fig. 2c). The seismicity in the following 5 months occurred over a wide area, at a rate not significantly different from the background seismicity prior to the sequence (Fig. 2c,d). We further find that the March 26 earthquake had a moment release duration of $9-10 \mathrm{~s}$ (for a magnitude $M_{\mathrm{w}}$ of 5.8), to be compared with the $5 \mathrm{~s}$ long duration observed for the $M_{\mathrm{w}} 6.0$ February 15 event. When normalized to an equivalent $M_{\mathrm{w}} 6.0$ earthquake ${ }^{23}$, the Source Time Functions (STF) for the February 9 and February 15 are similar in shape and duration to the average STF derived for the subduction earthquakes that occurred in the highly coupled subduction segment in Central and Southern Peru (Fig. 3a). On the contrary, the normalized STF for the March 26 earthquake shows a fairly long duration and low moment rate release throughout the rupture, two characteristics also shared by the $1960 M_{\mathrm{w}} 7.6$ and $1996 M_{\mathrm{w}} 7.5$ tsunami earthquakes ${ }^{20,21}$ (Fig. 3b). The March 26 therefore likely occurred within the weak, low rigidity material within the accretionary prism (Fig. 4e), which promotes a conditionally stable regime ${ }^{24}$ where 
slip is generally stable and aseismic, but can be seismic if it experiences significant rapid loading ${ }^{23}$.

The rate and amount of aseismic slip drastically increased after the March 26 event and was also detected at CGPS site PIU0, $\sim 80 \mathrm{~km}$ northeast from BAYO (Fig. 1 and Extended Data Figure 2). The post March 26 earthquake transient displacement represents $\sim 70 \%$ of the cumulated displacement observed at site BAYO, despite a moment twice smaller than the February 15 event and a more remote location from GPS site BAYO. Finally, a crustal $M_{\mathrm{w}} 5.3$ earthquake on August 27 marks the end of the sequence (Fig.1 and 2e). Its normal focal mechanism indicates that the stress previously released was large enough to reactivate a normal fault within the upper plate.

The logarithmic-like displacement seen in the BAYO GPS time series is similar to the post-seismic deformation observed after many earthquakes ${ }^{2,16}$, but with an unusually large aseismic/seismic moment ratio for the Mw 5.8 March 26 tsunami-type earthquake. Indeed, considered separately, the aseismic/seismic ratio for this event is $>1000 \%$. Such a ratio falls between the ones found for classical earthquake-afterslip sequences and for SSE.

Afterslip is commonly interpreted within the rate-and-state friction law framework ${ }^{24}$ as the response of velocity-strengthening areas nearby the rupture to the sudden stress increment induced by the earthquake. The stress increment leads to an instantaneous increase of the sliding velocity in the nearby velocity-strengthening areas, which then decreases through time at logarithmic decay ${ }^{25}$. In Fig. 1, we show the transient displacement predicted by a simple spring-slider model with a velocity-strengthening law superimposed to BAYO GPS time series (Supplementary Information). Although a good fit to the GPS time series is achieved by this model, it leads to some unrealistic physical parameters: because the stress increment induced by the co-seismic slip scales with the logarithm of the velocity increment, the March 
26 earthquake should have generated a Coulomb stress increment at least 5 times larger than that of the February 15 earthquake, despite a 2 times smaller moment; because no significant co-seismic offset was detected at GPS site BAYO after the March 26 earthquake, we can exclude that the March 26 earthquake had an abnormally large slip (Supplementary information). Furthermore, within the simple model of velocity-strengthening response to a sudden stress increment, the amount of triggered afterslip scales with the Coulomb stress change induced by the earthquake divided by the equivalent stiffness of the medium where afterslip occurs $^{25}$. Previous large afterslip cases ${ }^{9,18,26}$ are consistent with this view. Here, the Coulomb stress increment within the slip area is found to be of the order of a few $\mathrm{kPa}$ at most, unlikely to be able to produce the centimeter level slip observed here (Supplementary Information). A stress perturbation of a few $\mathrm{kPa}$ is a typical value that has been proposed for triggering or modulating SSE and $\mathrm{NVT}^{27-29}$. Together with the absence of seismicity following the March $26^{\text {th }}$ earthquake, this correlation favors the view that the post March 26 aseismic slip was a slow slip "helped" by an earthquake rather than classical afterslip. Results of the slip inversion suggest that part of the aseismic slip took place in the conditionally stable area close to the March $26^{\text {th }}$ earthquake (Fig. 4e).

Seismic Swarms (SS) are commonly observed along megathrust subduction zones ${ }^{30}$. Although SS relationship to aseismic slip has been proposed, very few observations have actually constrained the size and time evolution of the associated aseismic slip. The northern Peru 2009 sequence shows how different areas of the subduction interface can interact through time and space at distances several times larger than the size involved in individual sub-sequences (Fig. $2 \& 4$ ). The mixed seismic and aseismic behaviors observed during the sequence witness the spatially variable frictional properties of a weakly coupled subduction interface. While seismicity and NVT triggered by SSE and aseismic slip triggered by earthquakes had been recognized separately, it shows that more complex interactions can 
exist between the two modes of slip. In that sense, the 2009 northern Peru sequence suggests that Synchronous Slow Slip and Seismic Swarms at subduction megathrusts define a specific category of stress release process.

\section{Methods summary}

We use the cumulative displacement registered at 2 continuous and 9 campaign GPS to invert the slip distribution along the subduction interface. We use seismograms from seismic networks to relocate the seismicity and estimate magnitudes. We use a deconvolution approach to calculate the source time functions of the Peru subduction earthquakes. We model the time dependent motion observed at continuous GPS site BAYO using the rate-and-state formalism for a simple spring-slider model.

\section{Methods}

\section{GPS}

We analyze the GPS data using the GAMIT/GLOBK 10.50 software $^{31}$ to derive daily estimates of GPS sites positions. In order to improve the precision of our time series over the studied area, we define a local reference frame using 6 continuous GPS sites surrounding northern Peru that is then used to express our time series. We derive the displacements at 11 GPS and associated uncertainties (Extended Data Fig. 1, Supplementary Information Table 1) using least-squares and by simultaneously fitting a position at a reference epoch, a velocity and an offset on the horizontal components.

\section{Inversion}

We invert the slip distribution along the plate interface using the GPS displacements as input data. We discretize a $250 \mathrm{~km}$ long segment of the subduction interface with 533 triangular 
subfaults from the trench to a depth of $60 \mathrm{~km}$ using a geometry modified from ref. ${ }^{32}$. We calculate the Green's function relating the unit slip for a fixed rake of $90^{\circ}$ of each subfault to the displacement components at the GPS sites for a homogeneous elastic semi-infinite space $^{33}$. We use a least-squares inversion with regularization constraints ${ }^{34}$ to retrieve the slip and perform a resolution analysis of the inversion results ${ }^{35}$. Our results show that the downdip limit of the slip distribution is well constrained by the data and that 75 to $90 \%$ of the moment was released at depths shallower than $20 \mathrm{~km}$, the deeper slip distribution being in the vicinity of the $M_{\mathrm{w}} 6.0$ February 15 earthquake. The area of significant slip involves a $80 \mathrm{~km}$ long segment of the subduction. The uncertainty for the slip amount and the slip spatial distribution increases with the distance from the coast. As a consequence, the western extent of the main slip patch is not resolved and larger slip than shown in Fig. 2F might have occurred close to the location of the March 26 earthquake. We find that the range of the total moment is conservatively in the range of 1.11-1.83E19 N.m with a preferred value of 1.20E19N.m equivalent to $M_{\mathrm{w}}$ 6.7. Fig. $2 \mathrm{~F}$ shows a model derived using minimum laplacian smoothing constraints and is selected using a L-curve criterion. The wrms for this model is $1.0 \mathrm{~mm}$.

\section{Seismicity}

We use 5 stations of the National Seismic Network of the Geophysical Institute of Peru and 8 stations from a temporal local seismic network to analyze the seismicity for the period mid2008 to mid-2010. We select 223 events (among them 102 belong to the 2009 sequence) with a minimum of $4 \mathrm{P}$ - and $\mathrm{S}$ - arrival times. We estimate the detection level to be $\mathrm{M}_{\mathrm{L}} \sim 3.2$. We simultaneously derive a new 1-D velocity model and hypocenter location, using the Velest program $^{36}$. The estimated depths agree within a few kilometers with our subduction interface

geometry. We compute local magnitudes $\mathrm{M}_{\mathrm{L}}$, that we convert ${ }^{37}$ into $M_{\mathrm{w}}$ (see supplementary information) in order to evaluate the seismic moment released through earthquakes. 


\section{Source time functions}

Source Time Functions (STFs) are extracted from the teleseismic P body waves recorded at the stations of the Federation of the Digital Seismograph Networks (FDSN). For each earthquake, we use the SCARDEC method ${ }^{38}$ to retrieve the apparent STFs at each station, from which we compute the average STF. The duration of the main moment release is evaluated from the average STF, between the first and last point reaching $0.25 F_{m}$, where $F_{m}$ is the peak of the moment rate. Because earthquake scaling laws predict that the STF duration and amplitude evolve as $M_{0}^{1 / 3}$ and $M_{0}^{2 / 3}$ respectively ${ }^{23}$ (where $M_{0}$ is the seismic moment), we normalize the average STF (hereafter referred as NSTF) to a common seismic moment, here chosen equal to $M_{0}{ }^{r e f}=1.16 \times 10^{18} N \cdot m\left(M_{\mathrm{w}}=6.0\right)$ for producing the Fig. 3. For comparison, we compute the average NSTF of earthquakes for 10 interplate earthquakes in the nearby Central and Southern Peru subduction zone with depth between $20 \mathrm{~km}$ and 40km (see Supplementary Table T5). In Fig. 3b, we also show the NSTF of the 1996 and 1960 tsunami earthquakes, the latter coming from ref. ${ }^{23}$.

\section{Rate-and state model}

We model the time evolution of the westward displacement observed at GPS site BAYO using the rate-and-state formalism ${ }^{24}$ and a one-dimension spring-slider model. We use the analytical formulation proposed in ref. $^{25}$ that predicts the time evolution of slip for an area of velocity-strengthening submitted to a sudden stress increment induced by a co-seismic slip, that we modified for the case here of two successive earthquakes. The estimated parameters of the model are a co-seismic offset after the February 15 earthquake, the velocity increment after each earthquake and a relaxation time. The wrms of the fit is $1.2 \mathrm{~mm}$. Further details are provided in the Supplementary Information. 


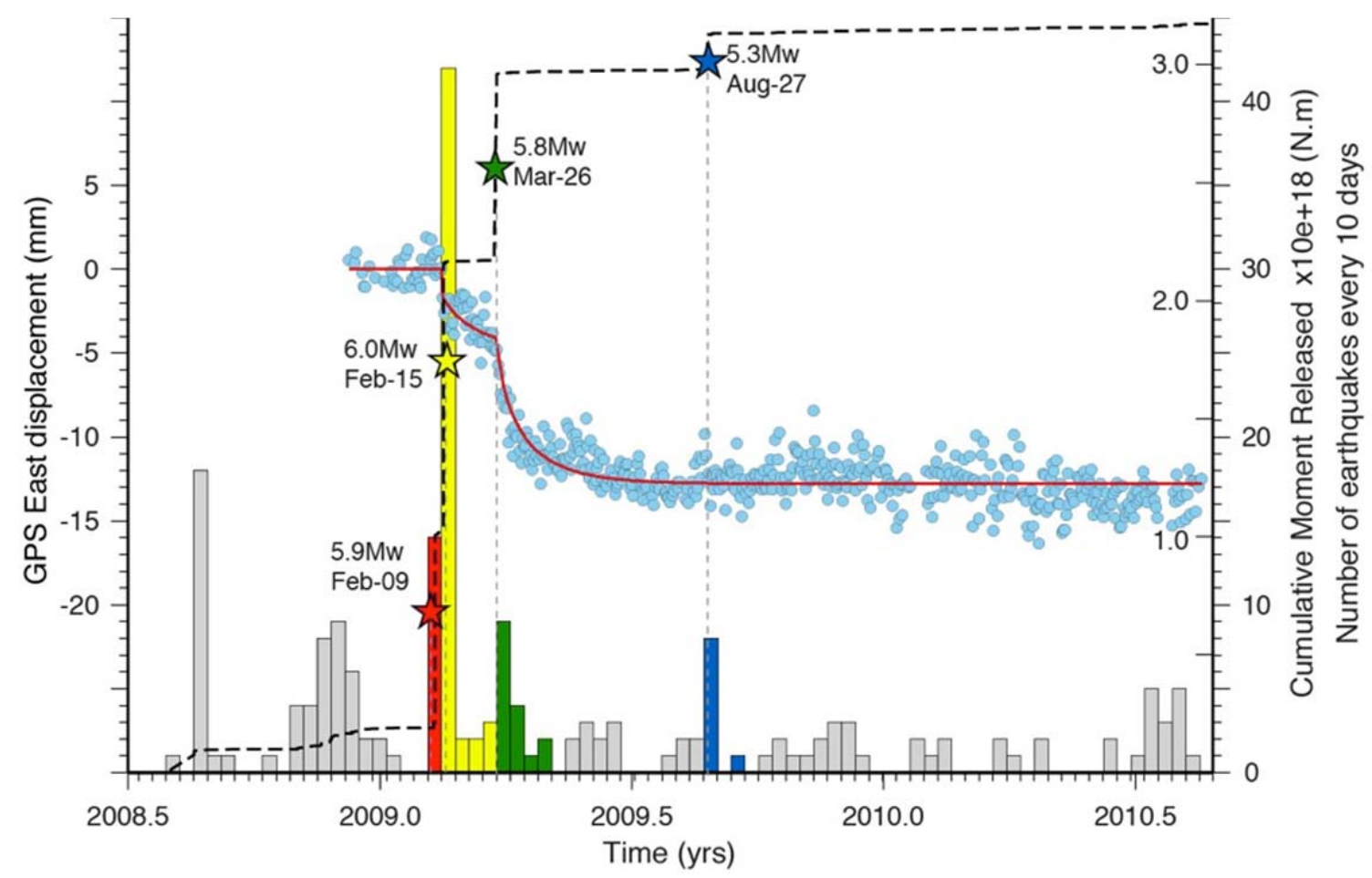

Fig. 1. Geodetic time series and seismicity rate from 2008.5 to 2010.65. Blue dots indicate the east displacement recorded at GPS site BAYO expressed with respect to the overriding plate (left axis). Histogram bars show the number of seismic events in 10 days intervals (outside right axis). Histogram colors correspond to the time periods of Fig. 2. The stars show the date of the four main earthquakes. Black dashed line represents the cumulated seismic moment through time (inside right axis). The red curve overprinting the GPS time series is the prediction from a simple spring-slider model with a velocity-strengthening friction law. 

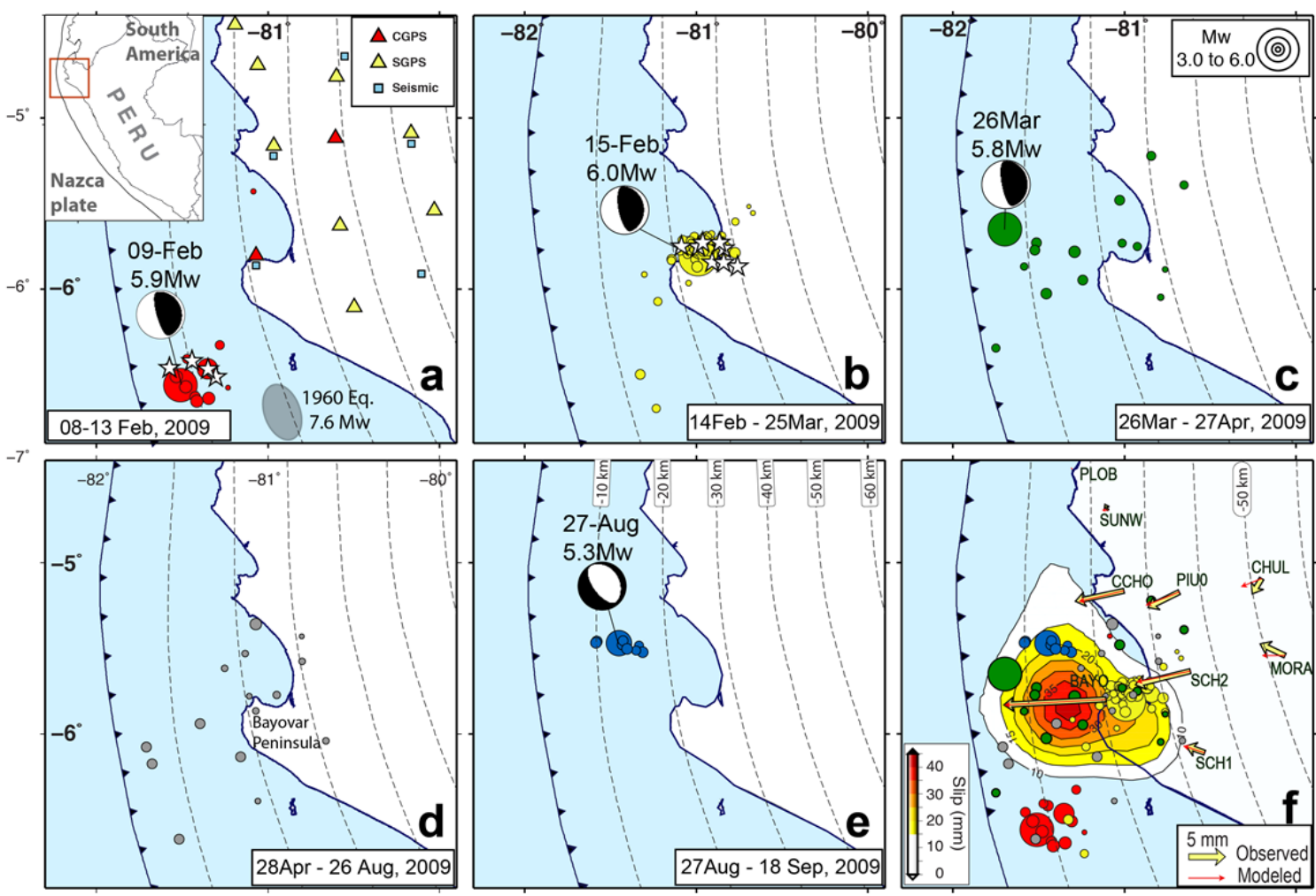

Fig. 2. Time evolution of seismicity during the sequence and associated total slip. 2a-2e: Seismicity for 5 time windows. Circles scaled to magnitude show the location of earthquakes together with the focal mechanism and magnitude for the four largest events. White stars are foreshocks. Light gray dashed lines are iso-depths of the subduction interface. The grey ellipse in $2 \mathrm{a}$ indicates the rupture area for the $1960 \mathrm{M}_{\mathrm{w}} 7.6$ tsunami earthquake ${ }^{20}$. 2f: Slip distribution of the total cumulative displacement. Colors represent slip in $\mathrm{mm}$ and lines indicate isovalues of slip every $5 \mathrm{~mm}$. Yellow and red arrows are observed and modeled GPS displacements respectively. 

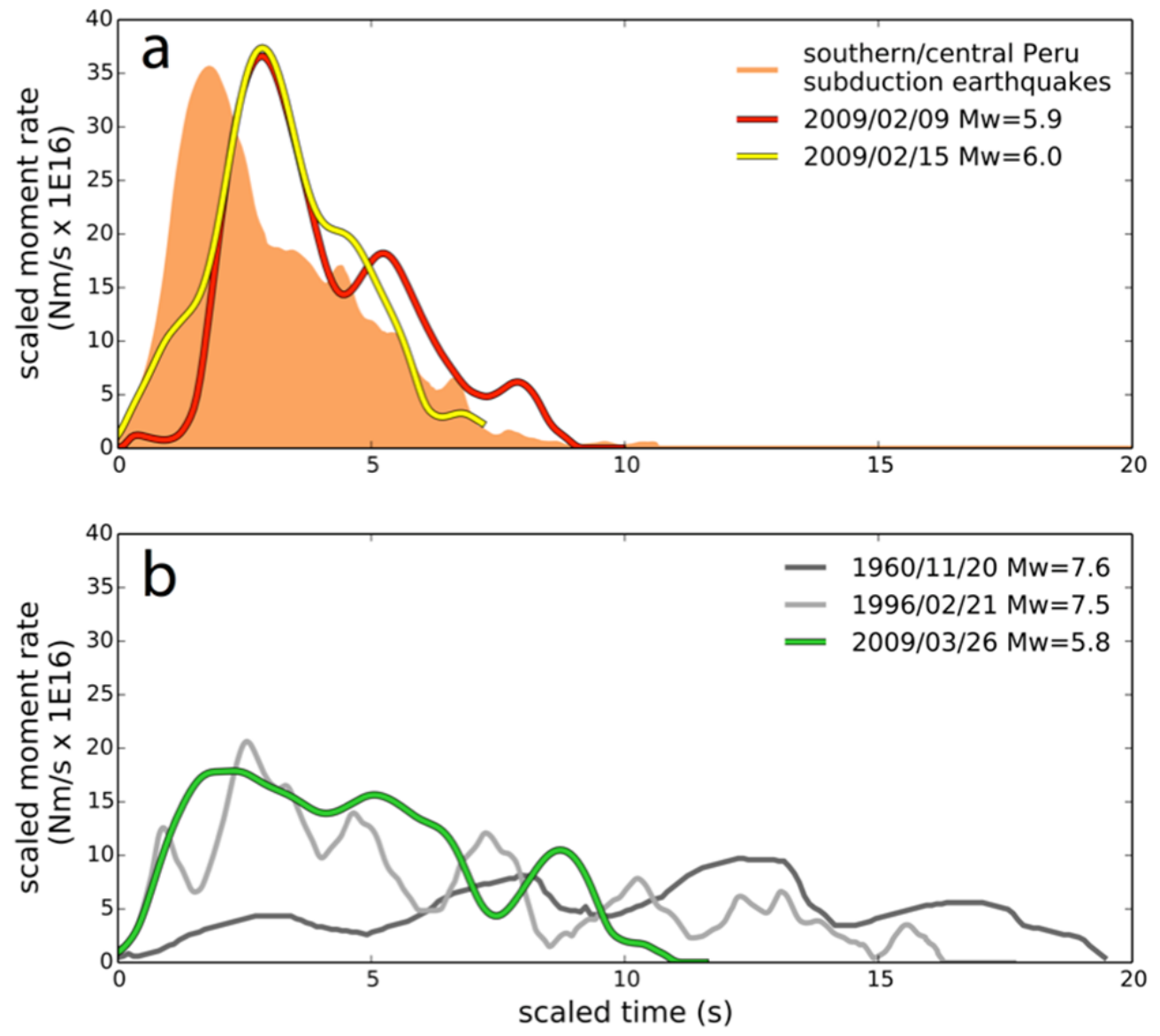

Fig. 3. Comparison of Normalized Source Time Functions (NSTF) for shallow interplate subduction earthquakes in Peru. The reference moment for normalization is $M_{\mathrm{w}} 6.0$. a. NSTF for the February 9 and 15 earthquakes together with the average NSTF for central and southern Peru subduction earthquakes. b. NSTF for the March 26 earthquake, together with the NSTF for the $1960 M_{\mathrm{w}} 7.6^{20}$ and $1996 M_{\mathrm{w}} 7.5^{21}$ tsunami earthquakes. NSTF shown in $\mathrm{b}$ have a peak moment rate half or less of that the average NSTF for Peru earthquakes, and have significantly longer duration. 

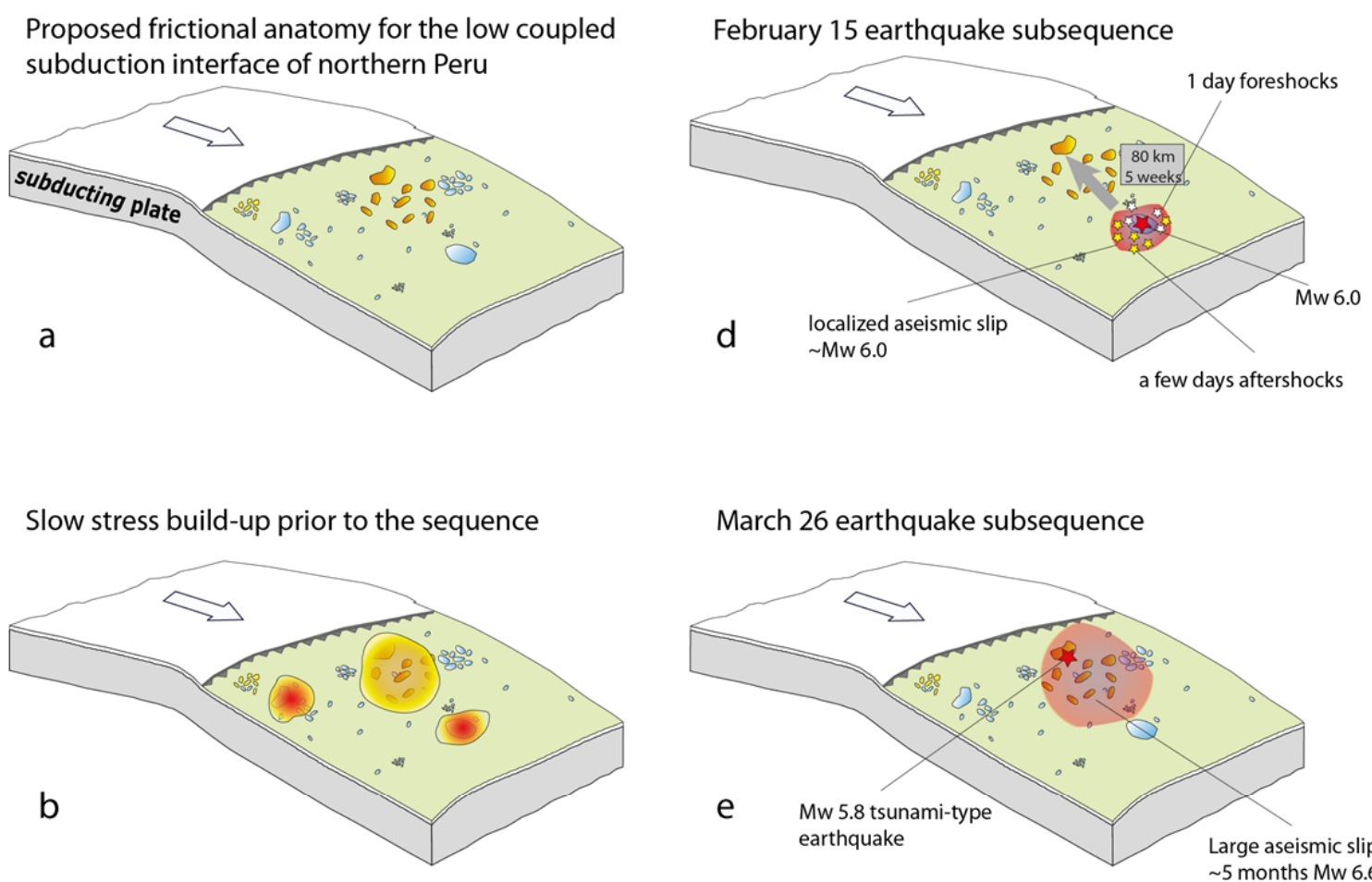

March 26 earthquake subsequence

February 9 earthquake subsequence
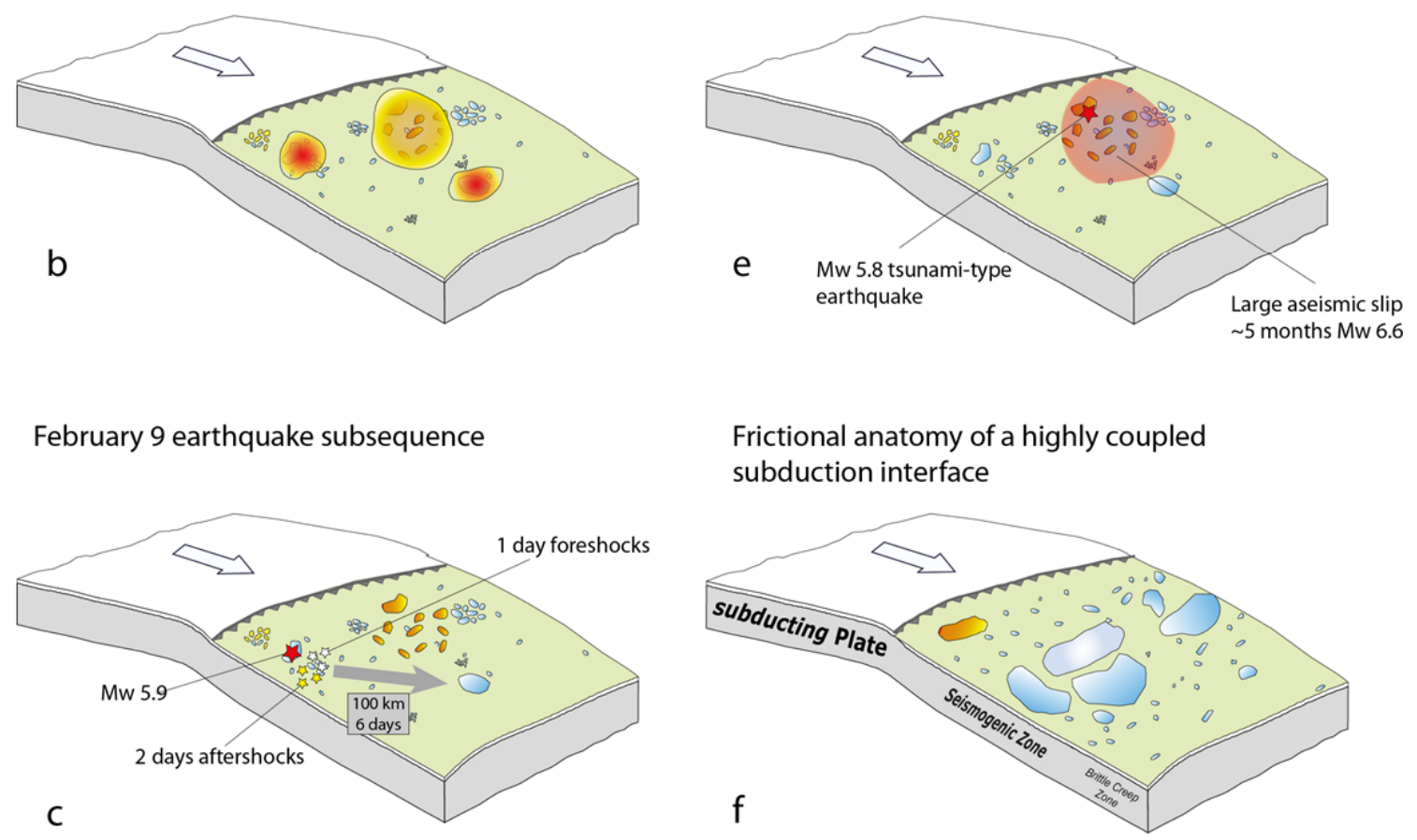

Frictional anatomy of a highly coupled subduction interface

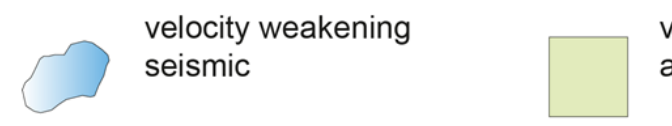

velocity strengthening

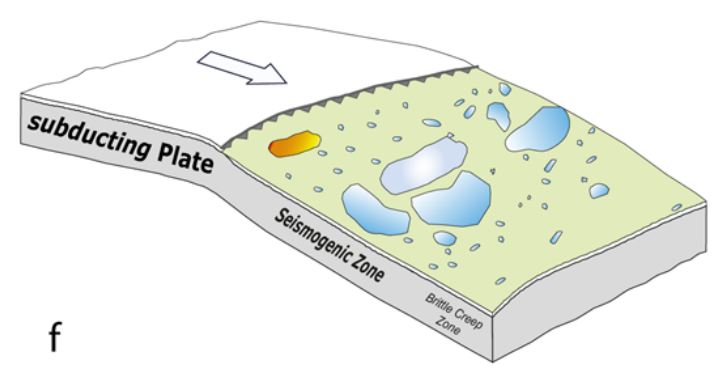
aseismic

conditionally stable usually aseismic but can be seismic

Fig. 4. Conceptual model of the 2009 northern Peru sequence. a. Proposed frictional anatomy for the low coupled subduction interface of northern Peru. b. Stress accumulation prior to the sequence. c, d, e. Foreshocks, mainshock and aseismic slip for the February 9, February 15, March 26 sub-sequences respectively. Grey arrows indicate the distance and time separation between a given sequence and the next one. f. For comparison, frictional anatomy for a highly coupled subduction interface. 


\section{References}

1. Dragert, H., Wang, K. \& James, T. S. A Silent Slip Event on the deeper Cascadia subduction interface. Science 292, 1525-1528 (2001).

2. Schwartz, S. Y. \& Rokosky, J. M. Slow slip events and seismic tremor at CircumPacific subduction zones. Rev. Geophys. 45, 1-32 (2007).

3. Hirose, H. \& Obara, K. Repeating short- and long-term slow slip events with deep tremor activity around the Bungo channel region, southwest Japan. Earth Planets Sp. 57, 961-972 (2005).

4. Rogers, G. \& Dragert, H. Episodic tremor and slip on the Cascadia subduction zone: the chatter of silent slip. Science 300, 1942-1943 (2003).

5. Ozawa, S., Suito, H. \& Tobita, M. Occurrence of quasi-periodic slow-slip off the east coast of the Boso peninsula, Central Japan. Earth Planets Sp. 59, 1241-1245 (2007).

6. Delahaye, E. J., Townend, J., Reyners, M. E. \& Rogers, G. Microseismicity but no tremor accompanying slow slip in the Hikurangi subduction zone, New Zealand. Earth Planet. Sci. Lett. 277, 21-28 (2009).

7. Vallée, M. et al. Intense interface seismicity triggered by a shallow slow slip event in the Central Ecuador subduction zone. J. Geophys. Res. 118, 2965-2981 (2013).

8. Pritchard, M. E. \& Simons, M. An aseismic slip pulse in northern Chile and alongstrike variations in seismogenic behavior. J. Geophys. Res. 111, B8405 (2006).

9. Suito, H., Nishimura, T., Tobita, M., Imakiire, T. \& Ozawa, S. Interplate fault slip along the Japan Trench before the occurrence of the 2011 off the Pacific coast of Tohoku Earthquake as inferred from GPS data. Earth, Planets Sp. 63, 615-619 (2011).

10. Nocquet, J.-M. et al. Motion of continental slivers and creeping subduction in the northern Andes. Nat. Geosci. 7, 287-291 (2014).

11. Ozawa, S., Murakami, M. \& Tada, T. Time-dependent inversion study of the slow thrust event in the Nankai trough subduction zone, southwestern Japan. J. Geophys. Res. 106, 787-802 (2001).

12. Wallace, L. M. \& Beavan, J. Diverse slow slip behavior at the Hikurangi subduction margin , New Zealand. J. Geophys. Res. 115, B12402, (2010).

13. Douglas, A., Beavan, J., Wallace, L. \& Townend, J. Slow slip on the northern Hikurangi subduction interface, New Zealand. Geophys. Res. Lett. 32, L16305 (2005).

14. Kao, H., Wang, K., Dragert, H., Kao, J. Y. \& Rogers, G. Estimating seismic moment magnitude $(\mathrm{Mw})$ of tremor bursts in northern Cascadia: Implications for the "seismic efficiency" of episodic tremor and slip. Geophys. Res. Lett. 37, L19306 (2010). 
15. Walter, J. I., Schwartz, S. Y., Protti, J. M. \& Gonzalez, V. Persistent tremor within the northern Costa Rica seismogenic zone. Geophys. Res. Lett. 38, L01307 (2011).

16. Perfettini, H. et al. Seismic and aseismic slip on the Central Peru megathrust. Nature 465, 78-81 (2010).

17. Heki, K., Miyazaki, S. \& Tsuji, H. Silent fault slip following an interplate thrust earthquake at the Japan Trench. Nature 386, 595-598 (1997).

18. Yagi, Y., Kikuchi, M. \& Sagiya, T. Co-seismic slip, post-seismic slip, and aftershocks associated with two large earthqaukes in 1996 in Hyuga-nada, Japan. Earth Planets Sp. 53, 793-803 (2001).

19. Bürgmann, R. et al. Rapid aseismic moment release following the 5 December, 1997 Kronotsky, Kamchatka, earthquake. Geophys. Res. Lett. 28, 1331-1334 (2001).

20. Pelayo, A. M. \& Wiens, D. A. The November 20, 1960 Peru Tsunami Earthquake: Souce Mechanism of a Slow Event. Geophys. Res. Lett. 17, 661-664 (1990).

21. Ihmle, P. F., Gomez, J.-M., Heinrich, P. \& Guibourg, S. The 1996 Peru tsunamigenic earthquake : Broadband source process. Geophys. Res. Lett. 25, 2691-2694 (1998).

22. Ekström, G., Nettles, M. \& Dziewonski, A. M. The global CMT project 2004-2010: Centroid-moment tensors for 13,017 earthquakes. Phys. Earth Planet. Inter. 201, 1-9 (2012).

23. Bilek, S. L. \& Lay, T. Tsunami earthquakes possibly widespread manifestations of frictional conditional stability. Geophys. Res. Lett. 29, 181-184 (2002).

24. Dieterich, J. H. Modeling of Rock Friction Experimental Results and Constitutive Equations. J. Geophys. Res. 84, 2161-2168 (1979).

25. Perfettini, H. \& Avouac, J. Postseismic relaxation driven by brittle creep: A possible mechanism to reconcile geodetic measurements and the decay rate of aftershocks, application to the Chi-Chi earthquake,Taiwan. J. Geophys. Res. 109, 2304 (2004).

26. Miyazaki, S., Mcguire, J. J. \& Segall, P. A transient subduction zone slip episode in southwest Japan observed by the nationwide GPS array. J. Geophys. Res. 108, 2087, (2003).

27. Hawthorne, J. C. \& Rubin, A. M. Tidal modulation of slow slip in Cascadia. J. Geophys. Res. 115, B09406 (2010).

28. Ozawa, S. Shortening of recurrence interval of Boso slow slip events in Japan. Geophys. Res. Lett. 41, 2762-2768 (2014).

29. Nadeau, R. M. \& Guilhem, A. Nonvolcanic tremor evolution and the San Simeon and Parkfield, California, earthquakes. Science 325, 191-193 (2009). 
30. Holtkamp, S. G. \& Brudzinski, M. R. Earthquake swarms in circum-Pacific subduction zones. Earth Planet. Sci. Lett. 305, 215-225 (2011).

\section{Reference for the Methods section}

31. Herring, T. A., King, R. W., Mcclusky, S. C. \& Sciences, P. Documentation of the MIT GPS Analysis Software: GAMIT v 10.40. (2010).

32. Hayes, G. P., Wald, D. J. \& Johnson, R. L. Slab1.0: A three-dimensional model of global subduction zone geometries. J. Geophys. Res. 117, B01302 (2012).

33. Okada, Y. Internal deformation due to shear and tensile faults in a half-space. Bull. Seismol. Soc. Am. 82, 1018-1040 (1992).

34. Tarantola, A. Inverse Problem Theory. SIAM, (2005).

35. Radiguet, M. et al. Slow slip events and strain accumulation in the Guerrero gap, Mexico. J. Geophys. Res. 117, B04305 (2012).

36. Kissling, E., Ellsworth, W. L., Eberhart-Phillips, D. \& Kradolfer, U. Initial reference models in local earthquake tomography. J. Geophys. Res. 99, 19635-19646 (1994).

37. Wells, D. \& Coppersmith, K. New Empirical Relationships among Magnitude, Rupture Length, Rupture Width, Rupture Area, and Surface Displacement. Bull. Seismol. Soc. Am. 84, 974-1002 (1994).

38. Vallée, M., Charléty, J., Ferreira, a. M. G., Delouis, B. \& Vergoz, J. SCARDEC: A new technique for the rapid determination of seismic moment magnitude, focal mechanism and source time functions for large earthquakes using body-wave deconvolution. Geophys. J. Int. 184, 338-358 (2011).

Supplementary Information is linked to the online version of the paper at www.nature.com/nature.

Correspondence and requests for materials should be addressed to J.C.V.L. (juancarlos.villegas@igp.gob.pe) or J-M. N. (nocquet@geoazur.unice.fr).

\section{Acknowledgements}

This work has been funded by the ANR (Agence Nationale de la Recherche, contract number ANR-07-BLAN-0143-01) and has continuously been supported by the IRD (Institut de Recherche pour le Développement). We thank J.P Ampuero from Caltech for the use of a 
broadband seismic stations from a temporary network in the frame of the Sisnort-08 project. JCVL acknowledges support provided by the IRD-DSF through a PhD grant.

\section{Author Contributions:}

JCVL and JMN did fieldwork, GPS analyzing, and inversion; JCVL did the seismicity analysis; JMN and FR performed the rate and state calculations; MV did the source time functions analysis; MC, FB and XM did GPS fieldwork; HT provided seismological data; TT did GPS analysis; JCVL, JMN and FR wrote the paper. All authors discussed the results and commented on the manuscript.

Author Information: Reprints and permissions information is available at www.nature.com/reprints. The authors declare no competing financial interests. Readers are welcome to comment on the online version of this article at www.nature.com/nature. 